\title{
Influence of workshop attendance on management of pediatric fecal incontinence in Nigeria
}

Taiwo Akeem Lawali

\begin{abstract}
Background: The care of children with fecal incontinence is suboptimal with inadequate support and training opportunities. The postgraduate training of pediatric surgeons on the management of fecal incontinence is inadequate since each training center is not likely to see enough number of cases yearly. Supplemental training through workshops on fecal incontinence may help to bridge the gap. The aim of this cross sectional study was to evaluate the impact of previous attendance of a workshop on fecal incontinence management practices among pediatric surgeons.

Results: A total of 41 respondents participated. Eleven (26.8\%) respondents had attended a workshop in the past and seven (17.1\%) had done a Malone antegrade continent enema (MACE) on patients. A higher proportion of respondents who had practiced for over 15 years had attended a workshop on fecal incontinence compared to those who had not attended one (90.9\% vs. 33.3\%, $p=0.001)$. The proportion of respondents who had attended a workshop on fecal incontinence and had performed a MACE (18.2\%) was higher than the proportion of those who had not attended a workshop and had performed a similar procedure on patients (3.3\%), $p=0.047$.

Conclusions: One quarter of pediatric surgeons in the country surveyed had attended a workshop on fecal incontinence. Prior attendance of a workshop on fecal incontinence is significantly related to experience and significantly influenced the performance of a MACE procedure. Supplementation of the training of pediatric surgeons through workshops on fecal incontinence will help to improve capacity in pediatric colorectal surgical care.
\end{abstract}

Keywords: Fecal incontinence, Pediatric colorectal surgery, Training, Workshops

\section{Background}

Anorectal malformations and spina bifida are the most common causes of fecal incontinence in children and it is estimated that 2265 newborn children in the USA are at risk for development of incontinence each year [1]. Other important causes include treatment for Hirschsprung disease, sacral agenesis, trauma, and tumors [1]. In pediatric colorectal practice, fecal incontinence occurs in 10 to $60 \%$ of patients who have had surgery for anorectal malformations and Hirschsprung disease [2-5].

The care of children with fecal incontinence is largely suboptimal with poor resource allocation and little in terms of advocacy outside pediatric surgical settings [1]. The options

Correspondence: tailove177@yahoo.com

Department of Surgery, College of Medicine, University of Ibadan and Division of Pediatric Surgery, University College Hospital, PMB 5116, Ibadan 200212, Nigeria

Springer Open of treatment include manipulation and use of diet, pharmacological agents, biofeedback mechanisms, surgery including artificial sphincters and colostomies, sacral nerve modulation, and bowel management using enemas $[1,2,6,7]$. Inappropriate choice of treatment modality, however, could lead to a worsening of the patient's overall health status and quality of life without resolution of the incontinence [7].

The care of these children is, quite often, a challenge as the surgeon prefers to operate and understands that it is not, many times, a solution in this instance while the pediatrician or gastroenterologist is not adequately trained or empowered to manage fecal incontinence. The onus, based on moral obligation and long-term post-operative follow-up needs then lies on the pediatric surgeon who is in charge of these patients to care for the child with fecal incontinence [1]. Inadequate training of pediatric surgeons on the management of fecal incontinence during 
postgraduate training could be a disadvantage since each training center is not likely to see enough number of cases on a yearly basis. Supplemental training through workshops on fecal incontinence, largely organized as pre-conference activities or through short-term fellowships at large-volume referral centers, may help to bridge the gap. Training activities such as workshops impact on professional practices and improve the outcome of care by attendees $[8,9]$. The study, therefore, aimed to evaluate the impact of previous attendance of a workshop on fecal incontinence management practices among pediatric surgeons.

\section{Methods}

This was a descriptive cross sectional survey conducted among pediatric surgeons in Nigeria. The study involved the use of structured self-administered questionnaires, which were distributed to attendees at the 17th annual general meeting and scientific conference of the Association of Paediatric Surgeons of Nigeria in September 2018. The questionnaire included sections on socio-demographic details, length of practice as physicians and pediatric surgeons, and attendance of workshop on pediatric fecal incontinence in the past. There were items on major causes of fecal incontinence in their practices, stoma nurse/therapist working with them, performance of Malone antegrade continence enema (MACE) on patients in their practices, compliance of patients with rectal enemas, cooperativeness of parents in administering the enemas and evaluation of patients with fecal incontinence as well as monitoring the outcome of administration of enemas. The questionnaires were anonymized. Ethical approval was obtained from the institution's ethics review board.

Data were entered into a computer using SPSS version 23 for statistical analysis. The data were summarized using modes, medians, and ranges for continuous variables and proportions and percentages for categorical data. Tests of association between categorical variables were conducted using Chi square statistics (and likelihood ratio when there were more empty cells than allowed for Chi square test). Continuous variables were dichotomized according to the median values for the purpose of bivariate analysis. The $p$ value for statistical significance was set at $<0.05$.

\section{Results}

A total of 41 respondents returned their questionnaires. There were $33(80.5 \%)$ males and the modal age groups were $41-45$ years $(11,26.8 \%)$ and over 50 years (11, $26.8 \%$ ). The respondents had practiced as physicians for 7 to 44 years (median of 15 years) and as pediatric surgeons for 1 to 38 years (median of 8 years). The leading causes of fecal incontinence as encountered in the practice of the respondents were anorectal malformations (17, 41.5\%), spinal cord anomalies (14, 34.1\%), and Hirschsprung disease $(6,14.6 \%)$.
Eleven (26.8\%) respondents had attended a workshop on fecal incontinence in the past. The number of workshops attended in the 5 years preceding the interview ranged from none to four (mode $=1$ ). Three $(7.3 \%)$ respondents had a stoma nurse/therapist working with them. Seven (17.1\%) respondents had done a Malone antegrade continent enema on one or more of their patients. Many $(28,70.0 \%)$ of the respondents observed that patients treated for fecal incontinence were somewhat compliant with daily rectal enemas; eight (20.0\%) said their patients were poorly compliant with the regimen. The majority $(33,82.5 \%)$ reported that most of the parents were cooperative in administering the daily enemas while three $(7.5 \%)$ noted that they had mostly uncooperative parents. Eleven (26.8\%) respondents used a scoring system to evaluate patients with fecal incontinence; six of these use Baylor and/or Cleveland scoring systems. In monitoring the response to daily rectal enemas, 12 (29.3\%) used digital radiographs, 10 (24.4\%) used ultrasound scans, and 9 (22.0\%) used a stool chart.

A higher proportion of respondents who had practiced for over 15 years had attended a workshop on fecal incontinence compared to those who had not attended one before $(90.9 \%$ vs. $33.3 \%, p=0.001)$. The proportion of respondents who had attended a workshop on fecal incontinence and had performed a MACE (18.2\%) was higher than the proportion of those who had not attended a workshop and had performed a similar procedure on their patients (3.3\%), $p=0.047$. There were no statistically significant associations between attendance of a workshop on fecal incontinence and other practices on fecal incontinence (Table 1).

\section{Discussion}

This survey conducted among pediatric surgeons practicing in a developing country showed poor support system for the management of children with fecal incontinence. It also revealed that prior attendance of a workshop on fecal incontinence is significantly related to experience, i.e., length of practice and significantly influenced the performance of a MACE procedure. It is a novel study evaluating the impact of attendance of workshop on practices concerning fecal incontinence by pediatric surgeons. A major limitation is that the cohort consisted of participants from the same country and there may be difficulty generalizing to other countries with different culture of attending workshops. Nonetheless, this study provided exploratory data, which will stimulate further interest in the role of surgeons in the management of fecal incontinence in children.

The major causes of fecal incontinence reported in this study were anorectal malformations and spinal cord anomalies. The two groups of malformations have been variously documented as the leading indications for referral to pediatric surgeons of patients with fecal incontinence $[1,3-$ 
Table 1 Association between experience, practices concerning fecal incontinence, and previous attendance of workshop

\begin{tabular}{|c|c|c|c|c|c|}
\hline \multicolumn{6}{|c|}{ Attended a workshop on fecal incontinence } \\
\hline Variables & $\begin{array}{l}\text { Attended } \\
\text { No (\%) }\end{array}$ & $\begin{array}{l}\text { Not attended } \\
\text { No }(\%)\end{array}$ & $\begin{array}{l}\text { Total } \\
\text { No (\%) }\end{array}$ & $x^{2}$ & $p$ value \\
\hline \multicolumn{6}{|l|}{ Length of practice (years) } \\
\hline$\leq 15$ & $1(9.1)$ & $20(66.7)$ & $21(51.2)$ & 10.679 & $0.001^{*}$ \\
\hline$>15$ & $10(90.9)$ & $10(33.3)$ & $20(48.8)$ & & \\
\hline \multicolumn{6}{|l|}{$\begin{array}{l}\text { Stoma nurse/therapist } \\
\text { available }\end{array}$} \\
\hline Yes & $2(18.2)$ & $1(3.3)$ & $3(7.3)$ & 2.617 & 0.106 \\
\hline No & $9(81.8)$ & $29(96.7)$ & $38(92.7)$ & & \\
\hline \multicolumn{6}{|l|}{ Done MACE on patient(s) } \\
\hline Yes & $4(36.4)$ & $3(10.0)$ & $7(17.1)$ & 3.951 & $0.047^{*}$ \\
\hline No & $7(63.6)$ & $27(90.0)$ & $34(82.9)$ & & \\
\hline \multicolumn{6}{|l|}{$\begin{array}{l}\text { Patients compliance } \\
\text { with rectal enemas }\end{array}$} \\
\hline Very compliant & $2(18.2)$ & $2(6.9)$ & $4(10.0)$ & $1.020^{\#}$ & 0.600 \\
\hline Somewhat compliant & $7(63.6)$ & $21(72.4)$ & $28(70.0)$ & & \\
\hline Poorly compliant & $2(18.2)$ & $6(20.7)$ & $\begin{array}{l}8 \\
(20.0)^{@}\end{array}$ & & \\
\hline
\end{tabular}

Cooperativeness of parents

in administering rectal

enemas

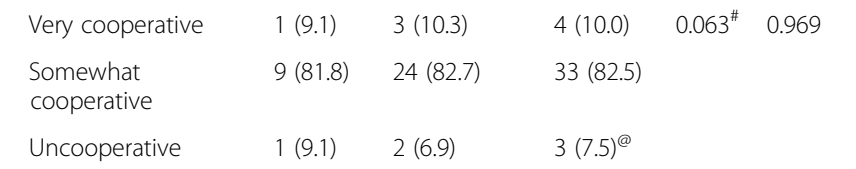

Scoring system used to evaluate patients with fecal incontinence

$\begin{array}{llllll}\text { Yes } & 5(45.5) & 6(20.0) & 11(26.8) & 2.657 & 0.103 \\ \text { No } & 6(54.5) & 24(80.0) & 30(73.2) & & \end{array}$

Digital radiograph to monitor treatment of fecal incontinence

\begin{tabular}{|c|c|c|c|c|}
\hline Yes & $5(45.5)$ & 7 (23.3) & $12(29.3)$ & 1.90 \\
\hline No & $6(54.5)$ & $23(76.7)$ & $29(70.7)$ & \\
\hline
\end{tabular}

Abdominal USS to monitor treatment of fecal incontinence

$\begin{array}{llllll}\text { Yes } & 2(18.2) & 8(26.7) & 10(24.4) & 0.314 & 0.575 \\ \text { No } & 9(81.8) & 22(73.3) & 31(75.6) & & \end{array}$

Stool chart to monitor treatment of fecal incontinence

\begin{tabular}{rlllll} 
Yes & $1(9.1)$ & $8(26.7)$ & $9(22.0)$ & 1.451 & 0.228 \\
No & $10(90.9)$ & $22(73.3)$ & $32(78.0)$ & & \\
Total & 11 & $30(100.0)$ & 41 & \\
& $(100.0)$ & & $(100.0)$ & \\
\hline
\end{tabular}

\footnotetext{
"Likelihood ratio
}

${ }^{\circledR}$ One respondent did not answer this question

*Statistically significant

MACE Malone antegrade continent enema
5]. Anorectal malformations, occurring in a spectrum, are commonly associated with fecal incontinence at the upper end of the spectrum. Patients with recto-bladder neck fistula, cloacal exstrophy, and similar severe malformations are prone to developing fecal incontinence $[4,10]$. This is worsened in the presence of poor prognostic factors such as absence of the sacrum or missing sacral vertebra, poor sacral ratios, absent kidneys, and associated malformations in the pelvis $[4,11]$.

Hirschsprung disease was comparatively a less common cause of fecal incontinence in this study. Fecal incontinence occurring after a pull-through procedure is an avoidable complication that may severely affect the quality of life of patients with Hirschsprung disease. The most plausible explanation for the incontinence in this patient is destruction of the anal canal by making the coloanal anastomosis at the anal verge instead of proximal to the dentate line [12]. The value of preserving the anal canal in pull-through procedures for Hirschsprung disease in order to prevent fecal incontinence cannot be overemphasized [12].

Just about a quarter of the pediatric surgeons in this study had attended a workshop on fecal incontinence in the past. This proportion is quite low considering the population of patients at risk and the fact that in many instances, treatment is for a very long time or for life. Less than one in ten pediatric surgeons had a stoma nurse/ therapist working with him/her. These together are indicative of poor systemic support for training on fecal incontinence care and inadequate workforce to complement the surgeon in teaching and supervision of enema administration. Stoma nurses or nurses that are well trained in the management of fecal incontinence are quite valuable in any bowel management program [1]. Inadequate funding is the most probable cause of these deficiencies. They may also be due to failure to recognize fecal incontinence as an important aspect of pediatric healthcare.

Daily enemas are increasingly being adopted by pediatric surgeons to treat patients with fecal incontinence [13-15]. Enemas are easy to administer, rectally in younger children and via appendicostomies or other conduits in older children after rectal enemas have been shown to be effective $[1,15]$. The administration of the enema, which is individualized based on colonic size and motility, allows the patient to be clean in between enemas and have a reasonably acceptable quality of life $[1,14,16]$. Retrograde administration of enemas is, however, fraught with issues of compliance, the dependence on a care-person and hence being uncomfortable for older children [17]. Antegrade enemas, popularized by Malone [14] are more readily acceptable, convenient, and cosmetically tolerated [13]. These involve administration of the enemas through conduits such as the appendix $[13,14,17,18]$ or cecum in patients who have had appendectomy or have had it used for a Mitrofanoff procedure [19]. 
Only a few $(17.1 \%)$ respondents had done a MACE procedure on one or more of their patients. It is, therefore, not surprising that a number of respondents in this study had patients who were poorly compliant with their daily enema administration, since most were administered rectally. From this study, there was a significant association between attending a workshop on fecal incontinence and having performed a MACE procedure. This is instructive as it confirms that training at the workshops had significant influences on the capability and capacity of the pediatric surgeon to deploy additional means of treatment that would impact on acceptability and compliance with enema administration. The recognition of the importance of attending such workshops may be the reason why more experienced pediatric surgeons were more likely to have attended workshops on fecal incontinence when compared to less experienced surgeons.

\section{Conclusions}

One quarter of pediatric surgeons in the country surveyed had attended a workshop on fecal incontinence. Prior attendance of a workshop on fecal incontinence is significantly related to experience and significantly influenced the performance of a MACE procedure. Supplementation of the training of pediatric surgeons through workshops on fecal incontinence will help to improve capacity in pediatric colorectal surgical care.

\section{Abbreviation}

MACE: Malone antegrade continence enema

\section{Acknowledgements}

The organizers of the conference in Kano, Nigeria and all respondents.

\section{Author's contributions}

TAL was the sole author of the work. The author read and approved the final manuscript.

\section{Author's information}

TAL is a pediatric surgeon, with major emphasis on pediatric colorectal care, practicing in a university teaching hospital in Nigeria. He received postfellowship pediatric colorectal training at the Colorectal Center for Children, Cincinnati Children's Hospital Medical Center, Cincinnati, USA, and the Center for Colorectal and Pelvic Reconstruction, Nationwide Children's Hospital, Columbus, USA, under the tutelage of Dr. Alberto Peña and Dr. Marc Levitt.

\section{Funding}

No external funding was received for the conduct of this study.

\section{Availability of data and materials}

The datasets used and/or analyzed during the current study are available from the corresponding author on reasonable request.

\section{Ethics approval and consent to participate}

Ethical approval was obtained from the joint University of Ibadan and University College Hospital Ethics Review Committee (UI/EC/18/0432). Verbal consent to participate was obtained from each respondent for the study. A verbal consent was obtained in each instance since this was a survey, which involved no personal data collection.

\section{Consent for publication}

Consent was obtained from each respondent to participate in the study.

\section{Competing interests}

The author declares that he has no competing interests.

Received: 25 September 2019 Accepted: 29 October 2019

Published online: 04 December 2019

References

1. Bischoff A, Levitt MA, Pena A. Bowel management for the treatment of pediatric fecal incontinence. Pediatr Surg Int. 2009;25:1027-42.

2. Elhalaby EA. Primary repair of high and intermediate anorectal malformations in the neonates. Ann Pediatr Surg. 2006;2:117-22.

3. Khazdouz M, Sezavar M, Imani B, Akhavan H, Babapour A, Khademi G. Clinical outcome and bowel function after surgical treatment in Hirschsprung's disease. Afr J Paediatr Surg. 2015;12:143-7.

4. Lawal TA. Overview of anorectal malformations in Africa. Front Surg. 2019;6:7.

5. Mathias AL, Tannuri AC, Ferreira MA, Santos MM, Tannuri U. Validation of questionnaires to assess quality of life related to fecal incontinence in children with anorectal malformations and Hirschsprung's disease. Rev Paul Pediatr. 2016;34:99-105.

6. Chiarioni G, Palsson OS, Asteria CR, Whitehead WE. Neuromodulation for fecal incontinence: an effective surgical intervention. World J Gastroenterol. 2013:19:7048-54.

7. Elfiky MM, Gad MA, Mohamed M, Kaddah SN, El Tagy GH. Implementation of a bowel management program in the treatment of incontinence in children for primary healthcare providers. Ann Pediatr Surg. 2017;13:21-5.

8. Davis D, O'Brien MAT, Freemantle N, Wolf FM, Mazmanian P, Taylor-Vaisey A Impact of formal continuing medical education: do conferences, workshops, rounds, and other traditional continuing education activities change physician behavior or health care outcomes? JAMA. 1999;282:867-74.

9. Kim H, Pandolfino JE, Komanduri S, Hirano I, Cohen E, Wayne DB. Use of a continuing medical education course to improve fellows' knowledge and skills in esophageal disorders. Dis Esophagus. 2011;24:388-94.

10. Hendren $\mathrm{WH}$. Cloaca, the most severe degree of imperforate anus: experience with 195 cases. Ann Surg. 1998;228:331-46.

11. Levitt MA, Peña A. Outcomes from the correction of anorectal malformations. Curr Opin Pediatr. 2005;17:394-401.

12. Levitt MA, Dickie B, Peña A. Evaluation and treatment of the patient with Hirschsprung disease who is not doing well after a pull-through procedure. Semin Pediatr Surg. 2010;19:146-53.

13. Lawal TA, Rangel SJ, Bischoff A, Peña A, Levitt MA. Laparoscopic-assisted Malone appendicostomy in the management of fecal incontinence in children. J Laparoendosc Adv Surg Tech A. 2011;21:455-9.

14. Malone $P$, Ransley $P$, Kiely E. Preliminary report: the antegrade continence enema. Lancet. 1990:336:1217-8.

15. Pfeifle VA, Holland-Cunz S. Bowel management in children: how to keep children clean. Ann Pediatr Surg. 2017;13:175-81.

16. Colares JH, Purcaru M, da Silva GP, Frota MA, da Silva CA, Melo-Filho AA, et al. Impact of the Bowel Management Program on the quality of life in children with fecal incontinence. Pediatr Surg Int. 2016;32:471-6.

17. Kiely EM, Ade-Ajayi N, Wheeler R. Antegrade continence enemas in the management of intractable faecal incontinence. J R Soc Med. 1995:88:103P-4P.

18. Rangel SJ, Lawal TA, Bischoff A, Chatoorgoon K, Louden E, Pena A, et al. The appendix as a conduit for antegrade continence enemas in patients with anorectal malformations: lessons learned from 163 cases treated over 18 years. J Pediatr Surg. 2011;46:1236-42.

19. Chatoorgoon K, Pena A, Lawal T, Hamrick M, Louden E, Levitt MA. Neoappendicostomy in the management of pediatric fecal incontinence. J Pediatr Surg. 2011;46:1243-9.

\section{Publisher's Note}

Springer Nature remains neutral with regard to jurisdictional claims in published maps and institutional affiliations. 